\title{
Assessment of Hepatic Arterial Anatomy in Keeping with Preservation of the Vasculature While Performing Pancreatoduodenectomy: An Opinion
}

\author{
Sung Hoon Yang $\cdot$ Yong Hu Yin · Jin-Young Jang \\ Seung Eun Lee $\cdot$ Jin Wook Chung $\cdot$ Kyung-Suk Suh . \\ Kuhn Uk Lee $\cdot$ Sun-Whe Kim
}

Published online: 11 October 2008

(c) Société Internationale de Chirurgie 2008

\section{Erratum to: World J Surg}

\section{DOI 10.1007/s00268-007-9246-5}

In the above-mentioned article, published in the issue of the World Journal of Surgery, volume 31 issue 12, the incorrect corresponding author was inadvertently listed. The correct contact for correspondence should read:
Sun-Whe Kim, MD, PhD. Department of Surgery, Seoul National University College of Medicine, Seoul National University Hospital, 28 Yongon-dong, Chongno-gu, Seoul, 110-744, Korea. Telephone: 82-2-2072-2315; Fax: 82-2766-3975; E-mail: sunkim@plaza.snu.ac.kr

The online version of the original article can be found under doi:10.1007/s00268-007-9246-5.

S. H. Yang $\cdot$ J.-Y. Jang $\cdot$ S. E. Lee $\cdot$ K.-S. Suh ·

K. U. Lee · S.-W. Kim $(\bowtie)$

Department of Surgery, Seoul National University College of Medicine, Seoul National University Hospital, 28 Yongon-dong, Chongno-gu, Seoul 110-744, Korea

e-mail: sunkim@plaza.snu.ac.kr

S. H. Yang

e-mail: moljin@korea.com

Y. H. Yin · J. W. Chung

Department of Radiology, Seoul National University College

of Medicine, Seoul, Korea 